\title{
Chiroptical Differentiation of Twisted Chiral and Achiral Polymer
}

\section{Crystals}

Hai-Mu Ye,$\stackrel{\dagger, * *}{+*}$ John H. Freudenthal, ${ }^{\mathbb{I}}$ Melissa Tan, ${ }^{\dagger}$ Jingxiang Yang, ${ }^{\dagger}$ Bart $\mathrm{Kahr}^{\dagger, *}$

${ }^{\dagger}$ Department of Chemistry, New York University, New York City, NY 10003, United States

${ }^{\mathbb{I}}$ Hinds Instruments, 7245 NW Evergreen Parkway, Hillsboro, Oregon 97124, United States

${ }^{\ddagger}$ Department of Materials Science and Engineering, College of New Energy and Materials, China University of Petroleum, Beijing 102249, P. R. China

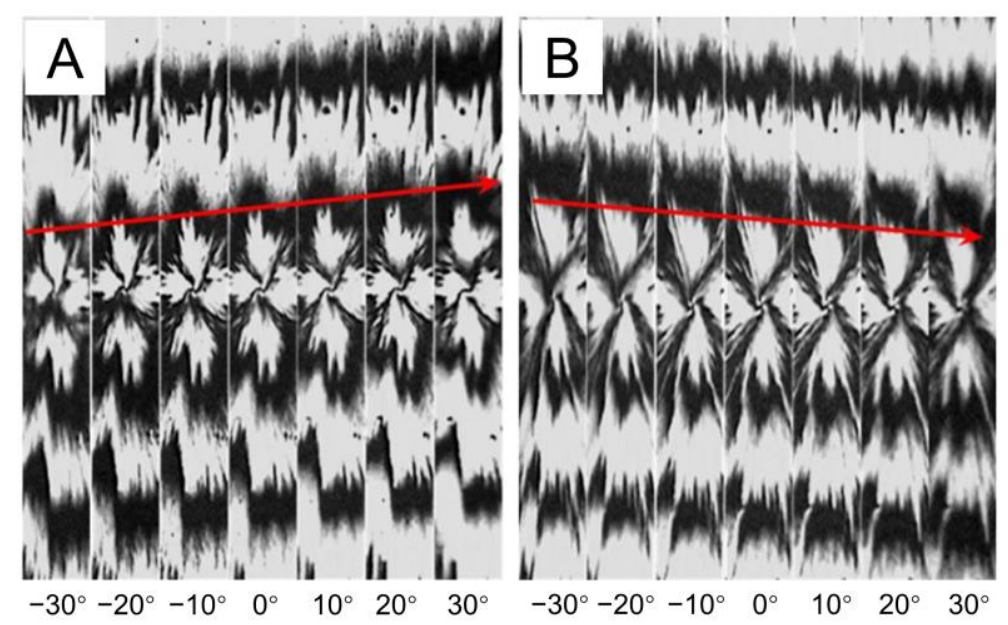

Figure S1. Sensing the screw measurement of (A) PDLA and (B) PLLA banded spherulites. The values at the bottom represent the angle of twist around the Y-axis in the right-handed positive sense. Up and down moving of band structure when rotating spherulites from $-30^{\circ}$ to $+30^{\circ}$ reveals left- and right-handed twist senses of PDLA and PLLA lamellae, respectively. 

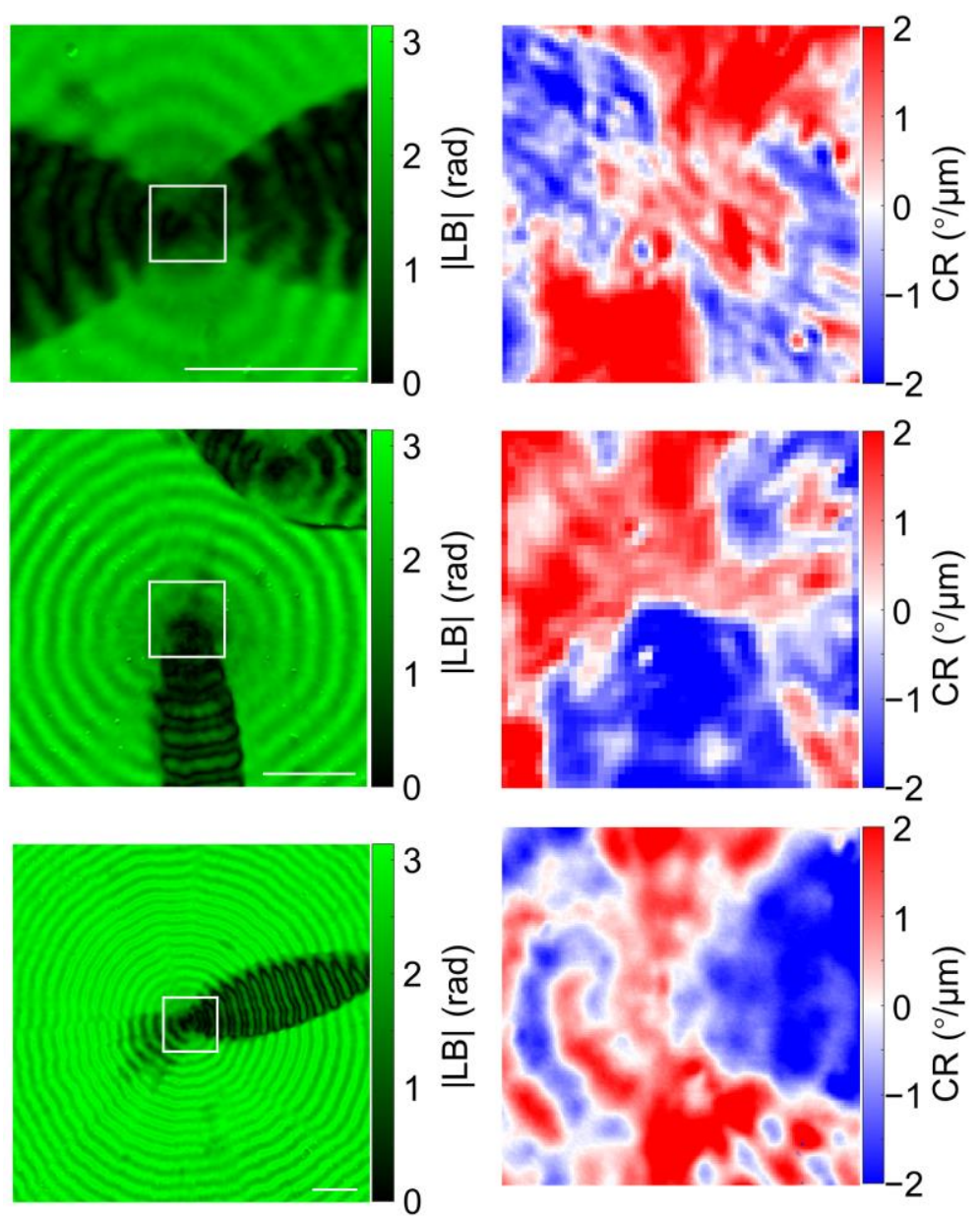

Figure S2. $|\mathrm{LB}|$ and CB micrographs of $(R)$-PHV banded spherulites. The scale bars are all $50 \mu \mathrm{m}$. 

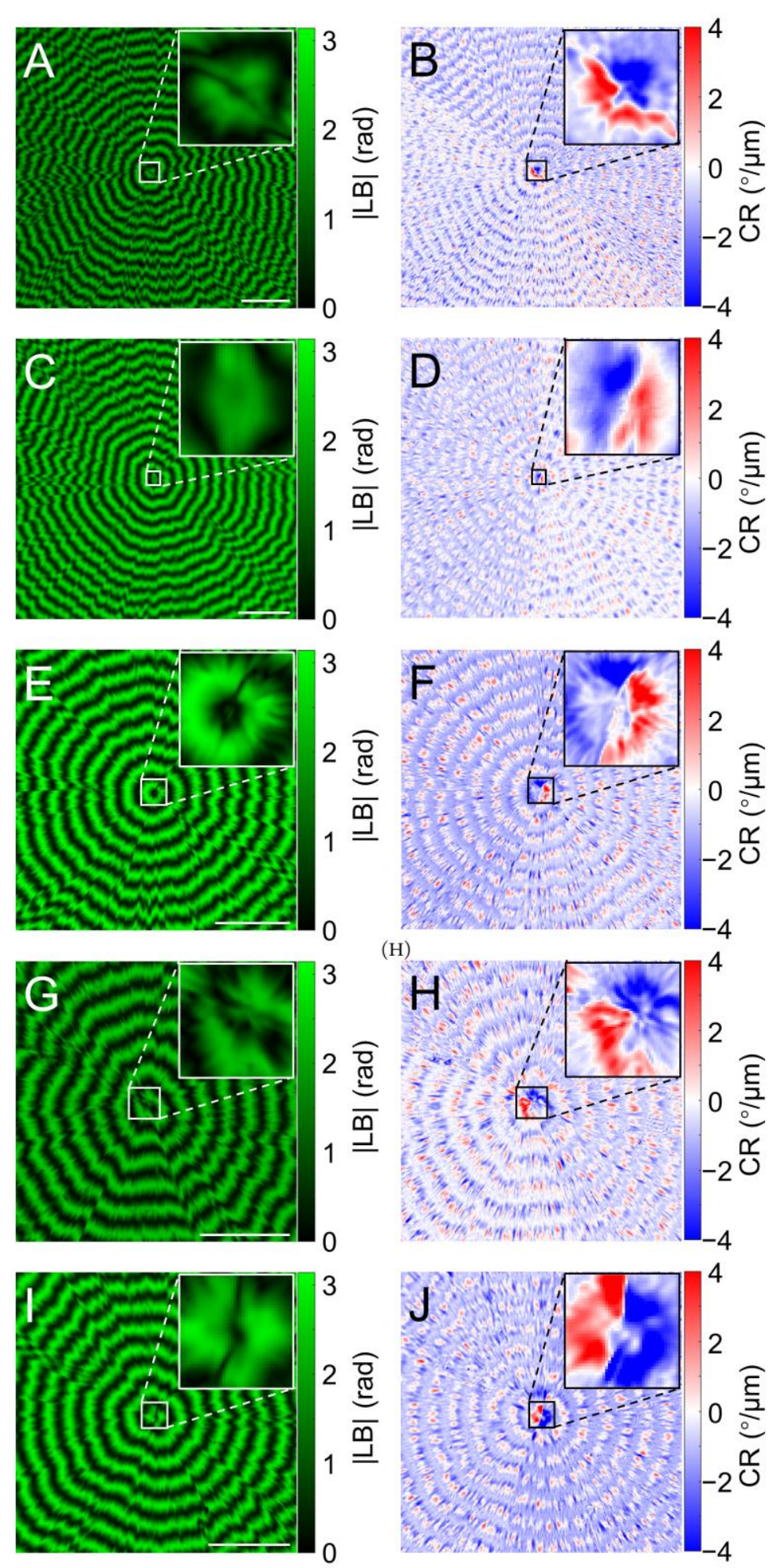

Figure S3. $|\mathrm{LB}|$, left colu mn, and CR, right column, mic rographs of PPF banded spherulites. In each micrograph, A-J, the cores are enlarged and inset in the upper right corner. The scale bars are all $50 \mu \mathrm{m}$. 


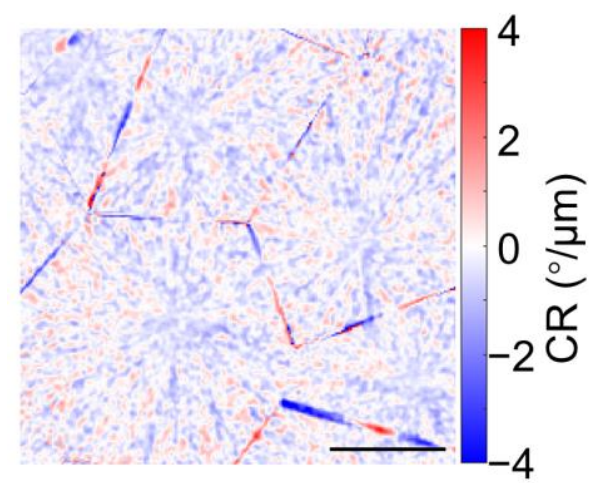

Figure S4. CB micrograph of smooth, PPF non-banded spherulites crystallized at $25^{\circ} \mathrm{C}$. The scale bar is $100 \mu \mathrm{m}$.
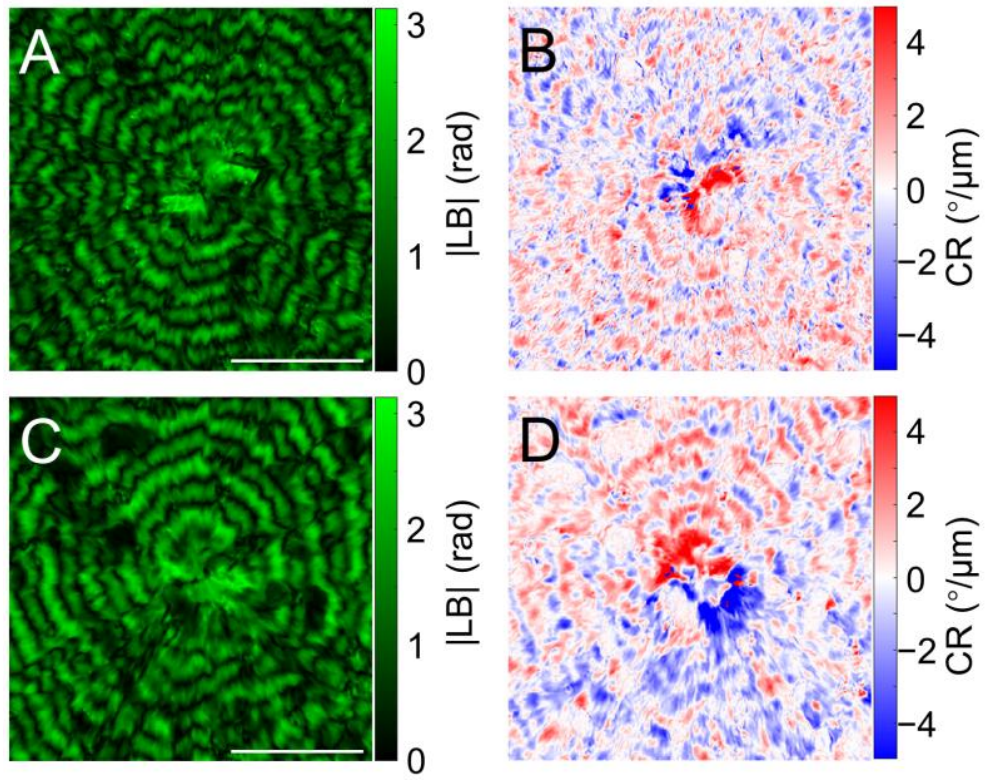

Figure S5. $|\mathrm{LB}|$ and CR micrographs of PBS banded spherulites. The scale bars are both $50 \mu \mathrm{m}$. 